\title{
Fiscal Policy and Stimuli to R\&D Investment with Uncertainty
}

\author{
Chien-Chieh Huang \\ Department of Economics, Soochow University \\ No.56 Kueiyang Street, Section 1, Taipei, Taiwan 100, R.O.C. \\ Tel.:+886-2-23111531 \#3430, E-mail: cxh213@scu.edu.tw \\ Wei-Wei Lee (Corresponding author) \\ Department of Economics, National Dong Hwa University \\ 1, Sec. 2, Da Hsueh Rd., Shou-Feng, 97401 Hualien, Taiwan, R.O.C. \\ Tel.: +886-3-8635539, E-mail: wwlee@mail.ndhu.edu.tw \\ Pai-Ta Shih \\ Department of Finance, National Taiwan University \\ Room 506, No. 85, Section 4, Roosevelt Road, Taipei, 106, Taiwan, R.O.C. \\ Tel: +886-2-33661093, E-mail: ptshih@management.ntu.edu.tw
}

Received: April 18, 2011

Accepted: May 5, 2011

doi:10.5430/rwe.v2n2p55

\begin{abstract}
Two models are examined in this study, namely, one incorporating exogenous investment and one incorporating endogenous investment and R\&D uncertainty. A lump-sum subsidy results in larger net tax revenues than does lowering the profit tax rate in the former model, while this may not be the case in the latter. In the latter model, a proportional investment subsidy generates the highest net tax revenues with low market volatility and always results in larger net tax revenues than does lowering the profit tax rate.
\end{abstract}

Keywords: Real option, R\&D, Irreversibility, Fiscal policies

\section{Introduction}

A significant body of research has investigated how fiscal policies affect the incentives of firms to undertake investment projects. The present analysis differs from those studies in that it examines the same issue from a government's perspective and it does so by incorporating certain characteristics of an investment project, irreversibility and uncertainty. More specifically, the aim of this research is to investigate which type of fiscal policy is able to generate the highest net tax revenues for the government from the investment project with a given trigger value.

A number of studies have used the real options approach to investigate the issue of the effect of fiscal policies on the investment decision. Mackie-Mason (1990), for example, studied the effect of a nonlinear tax policy on investment decisions and concluded that lowering corporate income tax may not encourage investments. Metcalf and Hassett (1994) allowed for uncertainty in tax policy and found that the level of investment grows when there is tax uncertainty, whereas it shrinks when there is price uncertainty. Interesting too, Agliardi (2001) incorporates tax uncertainty in his model to analyze how tax policies affect a firm's incentive to invest and disinvest.

Most studies that have explored the impact of fiscal policies on investing incentives have taken the point of view of firms and have considered uncertainty in the tax system. The exception is Pennings (2000) who clearly demonstrates that a subsidy coupled with taxation which makes for a zero expected cost to the government can reduce the trigger value of an investment project. The policy implication that emerges from his findings is that a lump-sum subsidy can generate higher net tax revenues for the government than can a reduced profit tax rate with an investment project of a given trigger value.

In this study, aside from the uncertainty of future profits, we incorporate another source of uncertainty that accompanies an $R \& D$ investment. It is assumed that the expected length of time required for successful implementation is random. 
How long it actually takes to successfully implement the project is probabilistic, and the probability distribution is assumed to be dependent on the endogenous amount of R\&D investment. The distinct characteristics of R\&D-intensive industries, such as software and pharmaceutical firms, seem to match these conditions well.

As concerns R\&D uncertainty, it can be traced as far back in the literature as the works of Dasgupta and Stiglitz (1980), Lee and Wilde (1980) and Reinganum (1983) in which R\&D uncertainty takes the form of a random relationship between the intensity of R\&D investment and the probability of a project's successful implementation. More recent studies, such as those of Goel (1995), Miyagiwa and Ohno (1997) and Weeds (2002), follow the same approach. While our set-up on R\&D uncertainty is in line with that in the literature, it departs from previous studies in that the amount of $R \& D$ investment here is endogenous.

In our model, any fiscal policy which affects the expected marginal benefits or expected marginal cost of a project affects the endogenous amount of R\&D investment, and this in turn has an influence on the probability of the successful implementation of the R \& D activity and tax revenues. We find that, under certain circumstances, lowering the profit tax rate can generate larger net tax revenues than a lump-sum subsidy under a given reduced trigger value. Such a result might well be in contrast with/ what Pennings (2000) implies. Thus, if the target industries are R\&D intensive, Pennings' (2000) conclusion may very well not be applicable.

This paper is organized as follows. Section 2 gives the model which incorporates an exogenous investment. Section 3 depicts the model with derivations in the case of R\&D uncertainty and endogenous investment. Section 4 provides the comparisons and discusses the impact of three policies on net tax revenues. The subsequent section concludes the study.

\section{The Model Parallel to Pennings' (2000)}

A firm considers the opportunity to engage in an R\&D activity which costs $I$ and generates a perpetual cash flow, $C F$. Following Pennings (2000), the investment cost $I$ is exogenous and fixed, and R\&D uncertainty is not considered. However, it should be noted that these assumptions will be relaxed in subsequent sections.

$C F$ is assumed to follow a geometric Brownian motion (GBM),

$d C F=\alpha C F d t+\sigma C F d z$

where the drift parameter $\alpha$ is less than the risk-free interest rate $r ; \sigma$ denotes market volatility; and $z$ is a Wiener process. Assume firm $i$ is risk-neutral. The present value of the perpetual cash flow, $V$, which is the value of the R\&D project, can be written as,

$V=\int_{0}^{\infty} \mathrm{E}\left(C F_{t}\right) e^{-r t} d t=\frac{C F}{r-\alpha}$

As $C F$ follows the geometric Brownian motion, so does $V$. The value to a firm of waiting to undertake the project is a function of $V$, which is $f(V)$. By Ito's lemma,

$d f=f^{\prime} d V+\frac{1}{2} f^{\prime \prime} \sigma^{2} V^{2} d t$

Assume the investment project is nontradable, and the risk of $V$ cannot be hedged by the assets in the market. The differential equation of $f(V)$ can be obtained with dynamic programming,

$E(d f)=r f d t$

Therefore,

$\frac{1}{2} \sigma^{2} V^{2} f^{\prime \prime}+\alpha V f^{\prime}=r f$

The solution to the differential equation $f(V)=A V^{\beta}$, where $A$ is a constant, and

$\beta=\frac{1}{2}-\frac{\alpha}{\sigma^{2}}+\sqrt{\left(\frac{\alpha}{\sigma^{2}}-\frac{1}{2}\right)^{2}+2 \frac{r}{\sigma^{2}}}$

Under the assumption, $\alpha<r, \beta$ is greater than 1 , and $\beta$ decreases in $\sigma$ (Note 1).

There exists a critical value of investment decision since the value of an $R \& D$ project is stochastic. As $V$ reaches the trigger value $\left(V^{*}\right)$ of the project, it is optimal for the firm to undertake the project; otherwise, the firm waits. 
The government is also risk-neutral and taxes the profits of corporations at the rate $t_{0}$ where $t_{0}$ represents the tax revenues the government collects from a one-unit increase in profits. Because taxes are collected on a continuous time basis, the firm actually bears the taxes as it undertakes the project and incurs investment cost $I$. However, at the very moment, net profit is negative. It appears that the government does not tax the firm at this time, but the truth is the government actually does tax the firm but collects zero tax revenue (Note 2). As a result, the value of waiting is

$$
\begin{aligned}
f(V) & =A V^{\beta} & & \text { if } V \leq V^{*} \\
& =\left(1-t_{0}\right) V-I & & \text { if } V \geq V^{*}
\end{aligned}
$$

Based on the continuity and smooth- pasting conditions,

$A V^{* \beta}=\left(1-t_{0}\right) V^{*}-I$

$A \beta V^{*(\beta-1)}=\left(1-t_{0}\right)$

$A$ and $V^{*}$ can be determined as

$A=\left(\frac{\beta-1}{\beta}\right)^{\beta-1} \frac{1}{\beta}\left(\frac{1}{I}\right)^{\beta-1}\left(1-t_{0}\right)^{\beta}$

$V^{*}=\frac{\beta}{(\beta-1)\left(1-t_{0}\right)} I$

From (11), the trigger value $V^{*}$ increases in the investment cost $I$. As the tax rate $t_{0}$ goes up, the after-tax profits drop, which leads to a rise in $V^{*}$. In addition, the greater the market volatility $\sigma$ is, the smaller is the parameter $\beta$, and the trigger value rises accordingly.

To compare with Pennings (2000), two policies are considered:

Policy A: granting a lump-sum subsidy, $S$;

Policy B: lowering the profit tax rate from $t_{0}$ to $t_{1}$.

The effects of the policy instruments are investigated under the assumption that investment $I$ is exogenous and fixed. The following analysis examines which policy induces larger expected tax revenues in reaching the same trigger value of an R\&D project.

Proposition 1. Comparing Policy A (a lump-sum subsidy) and Policy B (lowering profit tax rate), it is found that given the same reduced trigger value of investment:

(1) Policy A generates higher expected tax revenues than Policy B (Note 3);

(2) the greater market volatility $(\sigma)$ is, the greater are the differences between the expected tax revenues resulting from Policy $A$ and Policy $B$.

Proof: (1) If the tax rate is reduced to $t_{1}, t_{1}<t_{0}$, then the

$$
\begin{aligned}
f(V) & =A V^{\beta} & & V \leq V_{m}^{*} \\
& =\left(1-t_{1}\right) V-I & & V \geq V_{m}^{*}
\end{aligned}
$$

where $V_{m}^{*}$ is the trigger value of the project under this policy. Similar to the derivation of (11),

$$
V_{m}^{*}=\frac{\beta}{(\beta-1)\left(1-t_{1}\right)} I
$$

On the other hand, if a lump-sum subsidy is provided, then the waiting value to the firm is

$$
\begin{array}{rlrl}
f(V) & =A V^{\beta} & V \leq V_{s}^{*} \\
& =\left(1-t_{0}\right) V-I+S & V \geq V_{s}^{*}
\end{array}
$$

where $V_{s}^{*}$ is the trigger value under the relevant policy. Similarly, it can be derived as

$V_{s}^{*}=\frac{\beta}{(\beta-1)\left(1-t_{0}\right)}(I-S)$ 
Assume these two policies result in the same level of trigger value. From (13) and (15), we can obtain

$\frac{I}{1-t_{1}}=\frac{I-S}{1-t_{0}}$

Based on (13) and (16), the expected tax revenues under Policy B (lowering the profit tax rate) are

$t_{1} V_{m}^{*}=\frac{t_{1} I}{1-t_{1}} \frac{\beta}{\beta-1}=\frac{t_{1}(I-S)}{1-t_{0}} \frac{\beta}{\beta-1}$

The tax revenues under Policy A (lump-sum subsidy) are

$t_{0} V_{s}^{*}-S=\frac{t_{0}(I-S)}{1-t_{0}} \frac{\beta}{\beta-1}-S$

The difference is (17)-(18) which is

$\frac{\beta}{\beta-1} \frac{(I-S)}{1-t_{0}}\left(t_{1}-t_{0}\right)+S$

We know $t_{1}-t_{0}=\left(1-t_{0}\right)-\left(1-t_{1}\right),(19)$ can be written as

$\frac{\beta}{\beta-1}(I-S) \frac{\left(1-t_{0}\right)-\left(1-t_{1}\right)}{\left(1-t_{0}\right)}+S=\frac{\beta}{\beta-1}(I-S)-\frac{1-t_{1}}{1-t_{0}} \frac{\beta}{\beta-1}(I-S)+S$

By (16), $I /\left(1-t_{1}\right)=(I-S) /\left(1-t_{0}\right),(20)$ can be simplified as

$\frac{\beta}{\beta-1}(I-S)-\frac{\beta}{\beta-1} I+S=S\left(1-\frac{\beta}{\beta-1}\right)=\frac{-S}{\beta-1}<0$

Therefore, Policy A results in higher expected tax revenues.

The difference in the expected tax revenues under the two policies is $S /(\beta-1)$, and from (15),

$I-\frac{\beta-1}{\beta} V_{s}^{*}\left(1-t_{0}\right)=S$

Therefore,

$\frac{S}{\beta-1}=\frac{I}{\beta-1}-\frac{V_{s}^{*}\left(1-t_{0}\right)}{\beta}$

Given the same trigger value, we can obtain

$$
\frac{\partial}{\partial \sigma}\left(\frac{S}{\beta-1}\right)=\frac{-\beta^{2} I+(\beta-1)^{2} V_{s}^{*}\left(1-t_{0}\right)}{\beta^{2}(\beta-1)^{2}}\left(\frac{\partial \beta}{\partial \sigma}\right)
$$

Because

$$
\begin{aligned}
\beta^{2} I-(\beta-1)(\beta-1) V_{s}^{*}\left(1-t_{0}\right) & >\beta^{2} I-\beta(\beta-1) V_{s}^{*}\left(1-t_{0}\right) \\
& =\beta\left(\beta I-(\beta-1) V_{s}^{*}\left(1-t_{0}\right)\right)
\end{aligned}
$$

By (15)

$$
(25)=\beta^{2} S>0
$$

and $\partial \beta / \partial \sigma<0$, which results in $\frac{\partial}{\partial \sigma}\left(\frac{S}{\beta-1}\right)>0$. Therefore, as market volatility increases, the difference between the 
expected tax revenues resulting from the two policies expands.

The reason that the above conclusions are reached can be analyzed as follows. Similar to the derivation of (10), $A_{m}$ and $A_{s}$ stand for the determined variables in waiting values under Policy $\mathrm{B}$ and Policy A, respectively. Thus

$$
\begin{aligned}
& A_{m}=\left(\frac{\beta-1}{\beta}\right)^{\beta-1} \frac{1}{\beta}\left(\frac{1}{I}\right)^{\beta-1}\left(1-t_{1}\right)^{\beta}, \\
& A_{s}=\left(\frac{\beta-1}{\beta}\right)^{\beta-1} \frac{1}{\beta}\left(\frac{1}{I-S}\right)^{\beta-1}\left(1-t_{0}\right)^{\beta} .
\end{aligned}
$$

Thus, the ratio of the waiting value under Policy A to that under Policy B is

$$
\frac{A_{s}}{A_{m}}=\left(\frac{I}{I-S}\right)^{\beta-1}\left(\frac{1-t_{0}}{1-t_{1}}\right)^{\beta} \text {. }
$$

Given that $t_{0}>t_{1}$ and $(16)$, we know $I /\left(1-t_{1}\right)=(I-S) /\left(1-t_{0}\right)$. (29) can be given as

$$
\frac{A_{s}}{A_{m}}=\frac{1-t_{0}}{1-t_{1}}<1 .
$$

(30) shows that a lump-sum subsidy (Policy A) leads to a smaller waiting value than a decrease in the tax rate because the degree of uncertainty associated with the after-tax value, $\left(1-t_{0}\right) V$, in the case of giving subsidies falls below that in the case where the profit tax rate is lowered. Therefore, Policy A results in higher tax revenues than Policy B. This also explains Pennings (2000) in which a combination of subsidy to investment and taxation of future profits with a zero expected revenue decreases the trigger value of the investment because such a policy decreases the waiting value with the same net project value. Therefore, an increase in the investment tax credit financed with an increase in tax on profits decreases the trigger value of the investment.

Furthermore, an increase in $\sigma$ raises the waiting value. The difference between the waiting value under these two policies thus grows larger as $\sigma$ goes up, which in turn expands the difference in the net tax revenues under the relevant policies. Different industries are associated with different values of market volatility, and the second part of Proposition 1 indicates the superiority of lump-sum subsidies facing more volatile industries. This may provide a possible direction while making policies concerning such industries.

However, in reality, in addition to the uncertainty of future profits, there is another source of uncertainty, which accompanies R\&D. More specifically, how long it takes for an R\&D project to be successful could be random and depends on the amount of investment. Therefore, in the following section, a model with R\&D uncertainty and endogenous investment is developed, and which policy generates the highest net tax revenues for the government is examined.

\section{The Model Incorporating R\&D Uncertainty and Endogenous Investment}

A firm considers an R\&D project that generates a stochastic net cash flow $\left(x_{t}\right)$ at any future time $t$ when the project is successfully implemented. Net cash flow follows the geometric Brownian motion (GBM) process below:

$d x=\alpha x d t+\sigma x d z$

where drift rate $(\alpha)$ is assumed to be less than the risk-free rate $(r)$, and instantaneous market volatility is denoted as $\sigma$. The increment of a standard Wiener process is denoted as $d z$. Therefore, once the R\&D project has been successfully implemented, it can generate the value $v$ as follows:

$v=\left(1-t_{0}\right) \int_{0}^{\infty} \mathrm{E}\left(x_{t}\right) e^{-r t} d t=\frac{x}{r-\alpha}$

where $t_{0}$ is the initial marginal tax rate. Since the net cash flow follows a GBM, $v$ also follows a GBM.

The amount of investment required to implement the $\mathrm{R} \& \mathrm{D}$ project is endogenous and is denoted as $I$. In a departure from the literature on real options, this study takes R\&D uncertainty into account. In line with Lee and Wilde (1980), we assume that from the onset of this investment, successful implementation takes place randomly in accordance with a Poisson distribution with the arrival rate $\lambda(I)$. Therefore, the likelihood of the project's success at time $t$ follows an exponential distribution. The probability of successfully implementing the project at time $t$ is denoted as $P$ and 
$P=\lambda(I) e^{-\lambda(I) t}$

where $1 / \lambda(I)$ is the expected length of time required for its successful implementation. For analytical purposes, we assume that $\lambda(I)=\theta I$, where $\theta>0$.

We denote the value of the project as $f(v)$. We consider the situation when the implementation of the project begins. Suppose that the firm is risk-neutral. Given that the successful implementation follows a Poisson process, the expected present value of the project, once it has just been implemented, can be expressed as:

$f(v)=E\left[\int_{0}^{\infty} \lambda v(u) e^{-\lambda u} e^{-r u} d u\right]=\frac{\left(1-t_{0}\right) \theta v I}{r+\theta I-\alpha}$

When the R\&D project is idle, the value of the option to invest follows an ordinary differential equation of the form specified in Dixit and Pindyck (Note 4). The value of this idle project is equal to the value of the option to invest, and it is referred to as $A v^{\beta}$, where $A$ is a constant value to be determined, and

$\beta=(1 / 2)-\left(\alpha / \sigma^{2}\right)+\sqrt{\left(\left(\alpha / \sigma^{2}\right)-1 / 2\right)^{2}+\left(2 r / \sigma^{2}\right)}$

The market value of the project is subject to the trigger value $v^{*}$ such that

$$
\begin{aligned}
f(v)= & A v^{\beta} \quad \text { if } v \leq v^{*} \\
& =\frac{\left(1-t_{0}\right) \theta v I}{r+\theta I-\alpha}-I \text { if } v \geq v^{*}
\end{aligned}
$$

Based on the above specifications, the objective function of the maximization problem is $\left(1-t_{0}\right) \theta v I /(r+I \theta-\alpha)-I$, in which $I$ is endogenously determined as a function of $v$. When the first order condition is applied, the optimal $I(v)$ satisfies the following condition:

$\frac{\left(1-t_{0}\right) \theta v(r-\alpha)}{(r+\theta I(v)-\alpha)^{2}}=1$

Based on the boundary conditions, we have

$A v^{\beta}=\frac{\left(1-t_{0}\right) \theta I(v) v}{r+\theta I(v)-\alpha}-I(v)$

And

$\beta A v^{\beta-1}=\frac{d\left[\max \left(\frac{\left(1-t_{0}\right) \theta v I}{r+\theta I-\alpha}-I\right)\right]}{d v}$

Following the envelope theorem, (39) can be expressed as:

$\beta A v^{\beta-1}=\frac{\left(1-t_{0}\right) \theta I(v)}{r+\theta I(v)-\alpha}$

By (37), (38) and (40), we obtain the trigger value $v^{*}$ and the optimal amount of investment $I^{*}$ as follows,

$v^{*}=\left(\frac{\beta}{\beta-1}\right)^{2} \frac{(r-\alpha)}{\left(1-t_{0}\right) \theta}$

$I^{*}=\frac{(r-\alpha)}{\theta(\beta-1)}$

\section{Comparison of Different Fiscal Policies and Discussion}

Because it is a frequently employed policy to provide a proportional subsidy to R\&D investment, in this section, it is merely taken as another policy instrument. Therefore, we consider three possible policies, namely:

Policy A: granting a lump-sum subsidy, $S$; 
Policy B: lowering the profit tax rate from $t_{0}$ to $t_{1}$; and

Policy C: providing proportional investment subsidies, $\tau$ I(Note 5 ).

First, we derive the critical value of the R\&D project and the endogenous amount of the investment for each policy in the following proposition.

Proposition 2: The endogenous amount of investment for Policy A, Policy B and Policy $C$ proposed above are represented as $I A, I B$ and $I C$, respectively, and they are:

$I A=\frac{\frac{1}{\beta}+\sqrt{\left(\frac{1}{\beta}\right)^{2}-4 \frac{\beta-1}{\beta} \frac{\theta}{r-\alpha} S}}{2 \frac{\beta-1}{\beta} \frac{\theta}{r-\alpha}}$,

$I B=I C=\frac{r-\alpha}{\theta(\beta-1)}$.

Besides, the critical values of the investment for Policy A, Policy B and Policy C, proposed above, are represented as VA, $V B$ and $V C$, respectively, and they are:

$V A=\frac{1}{\theta(r-\alpha)} \times\left(r+\theta^{*} I A-\alpha\right)^{2} \times \frac{1}{\left(1-t_{0}\right)}$,

$V B=\frac{1}{\left(1-t_{1}\right)}\left(\frac{\beta}{(\beta-1)}\right)^{2} \frac{r-\alpha}{\theta}$,

$V C=\frac{(1-\tau)}{1-t_{0}}\left(\frac{\beta-1}{\beta}\right)^{2} \frac{r-\alpha}{\theta}$.

Proof: Please refer to the Appendix .

Now, if the government tries to induce the firm to invest earlier from the critical value $V j$ to $\kappa V j$, where $\kappa$ is called the reduced ratio and $j=A, B$ and $C$, we can compare the net tax revenues of the government based on these three policies (Note 6). The numerical results are shown in Table 1.

\section{$<$ Table 1 about Here>}

In Table 1, we find three interesting results. First, Policy A (the lump subsidy policy) is not always better than Policy B (reducing the profit tax rate) in generating tax revenues. Policy B possibly does a better job than Policy A when market volatility is low and the reduced ratio is high. The reason is that decreasing the profit tax rate not only increases uncertainty, but also increases the amount of investment, and therefore, a decrease in the expected length of time required for successful implementation, which increases the pre-tax value. Thus, with low market volatility and a high reduced ratio, the latter effect is more likely to dominate over the former, i.e. Policy B is better than Policy A. Otherwise, Policy A is better than Policy B in generating higher net tax revenues.

Second, we find that Policy C (proportional R\&D investment subsidies) is always better than Policy B, and this is confirmed in the following proposition.

Proposition 3: Given the same reduced critical value of the investment, Policy $C$ always results in larger net tax revenues than Policy $B$ does.

Proof: For Policy C, the net tax revenues $\operatorname{Tax} C$ is:

$\operatorname{Tax} C=\frac{t_{0} \theta^{*} I C * V C}{\gamma+\theta^{*} I C-\alpha}-\tau * I C$,

where

$V C=\frac{1-\tau}{1-t_{0}}\left(\frac{\beta}{\beta-1}\right)^{2} \frac{\gamma-\alpha}{\theta}$, 
$I C=\frac{\gamma-\alpha}{\theta(\beta-1)}$.

Therefore,

$$
\begin{aligned}
\frac{d \operatorname{Tax} C}{d V C} & =\frac{t_{0} \theta^{*} I C}{\gamma+\theta^{*} I C-\alpha}+\frac{d \tau}{d V C} I C \\
& =\frac{t_{0} \theta^{* I C}}{\gamma+\theta^{*} I C-\alpha}+\frac{\theta}{\gamma-\alpha}\left(\frac{\beta-1}{\beta}\right)^{2}\left(1-t_{0}\right) \frac{\gamma-\alpha}{\theta(\beta-1)} \\
& =\frac{t_{0}}{\beta}+\frac{\left(1-t_{0}\right)(\beta-1)}{\beta^{2}} \\
& =\frac{1}{\beta}-\frac{\left(1-t_{0}\right)}{\beta^{2}}
\end{aligned}
$$

On the other hand, for Policy $\mathrm{B}$, the net tax revenues $\operatorname{Tax} B$ is:

$\operatorname{Tax} B=\frac{t_{1} \theta^{*} I B * V B}{\gamma+\theta * I B-\alpha}$

where

$I B=\frac{\gamma-\alpha}{\theta(\beta-1)}$

$V B=\frac{1}{1-t_{1}}\left(\frac{\beta}{\beta-1}\right)^{2} \frac{\gamma-\alpha}{\theta}$.

Because

$t_{1}=1-\frac{1}{V B}\left(\frac{\beta}{\beta-1}\right)^{2} \frac{\gamma-\alpha}{\theta}$,

we have

$\operatorname{Tax} B=\frac{\theta^{*} I B * V B}{\gamma+\theta^{*} I B-\alpha}-\frac{\theta^{*} I B}{\gamma+\theta^{*} I B-\alpha}\left(\frac{\beta}{\beta-1}\right)^{2} \frac{\gamma-\alpha}{\theta}$.

Therefore,

$\frac{d \operatorname{Tax} B}{d V B}=\frac{\theta^{*} I B}{\gamma+\theta^{*} I B-\alpha}=\frac{1}{\beta}$.

Based on (51) and (57), we have $\frac{d T a x B}{d V B}>\frac{d T a x C}{d V C}>0$, and therefore, Policy $C$ always results in larger net tax revenues than

Policy B does with the same reduced trigger value of investment.

The reason that Policy $\mathrm{C}$ always results in larger net tax revenues than Policy $\mathrm{B}$ does in reaching the same trigger value is that, based on (44), both induce the same amount of investment, , but Policy B raises more uncertainty than Policy C. Hence, Policy $\mathrm{C}$ always results in larger net tax revenues than Policy B.

Finally, because of the first and second results (i.e., Policy B could be better than Policy A, and Policy C is always better than Policy B), it is clearly apparent that Policy C is likely the best policy to generate the largest net tax revenues under some circumstances.

\section{Conclusions}

This study investigates which type of fiscal policy yields the highest net tax revenues for a government given the same critical value of an R\&D project. Two models are examined, namely, one incorporating exogenous investment and the other incorporating endogenous investment and R\&D uncertainty. In the former model, it turns out that a lump-sum 
subsidy results in larger net tax revenues than does lowering the profit tax rate, whereas in the latter model, this may very well not be the case. In the latter model, the policy which generates the largest net tax revenues depends on the parameters, including market volatility and the reduced ratio. More specifically, a proportional investment subsidy generates the highest net tax revenues when there is low market volatility. In addition, a proportional investment subsidy always generates higher net tax revenues than does lowering the profit tax rate. The greater the market volatility is, the greater are the differences between the expected tax revenues resulting from the policy of a lump-sum subsidy and the policy of lowering the profit tax rate.

Three types of fiscal policy are considered in this study though it does not exclude other possibilities -- for example, a tax holiday alone or a combination of a lump-sum subsidy and a tax holiday. Not only is it interesting to investigate the effects of such a mixture on encouraging investment since there may be reinforcing and counteracting effects at the same time, but also it is extremely enlightening for policy-makers. Market structure and the interactions among firms, which are ignored in the present analysis, may also play an important role when examining this issue. It is thus worthwhile to incorporate these factors in future studies so as to determine further policy implications.

\section{References}

Agliardi, E. (2001). Taxation and investment decisions: A real options approach. Australian Economic Papers, 40, 44-55. http://dx.doi.org/10.1111/1467-8454.00112

Alvarez, L. \& Koskela, E. (2008). Progressive taxation, tax exemption, and irreversible investment under uncertainty. Journal of Public Economic Theory, 10, 149-469

Auerbach, A. (1986). The dynamic effects of tax law asymmetries. Review of Economic Studies, 53, 205-226

Dasgupta, P. \& Stiglitz, J. (1980). Uncertainty, industrial structure and the speed of R\&D. Bell Journal of Economics, 11, $1-28$

Dixit, A. \& Pindyck, R. (1994). Investment under uncertainty. Princeton University Press, NJ.

Goel, R. (1995). Spillovers, rivalry and R\&D investment. Southern Economic Journal, 62, 71-76

Hassett, K. \& Metcalf, G.. (1999). Investment with uncertain tax policy. Economic Journal, 109, 372-393

Lee, T. \& Wilde, L. (1980). Market structure and innovation: A reformulation. Quarterly Journal of Economics, 94, 429-436

Mackie-Mason, J. (1990). Some nonlinear tax effects on asset values and investment decisions under uncertainty. Journal of Public Economics, 42, 301-328

Miyagiwa, K \& Ohno, Y. (1997). Strategic R\&D and appropriability. Journal of International Economics, 42, 125-148

Niemann, R. \& Sureth, C. (2004). Tax neutrality under irreversibility and risk aversion. Economics Letters, 84, 43-47

Pennings, E. (2000). Taxes and stimuli of investment under uncertainty. European Economics Review, 44, 383-391

Pennings, E. (2005). How to maximize domestic benefits from foreign investments: The effect of irreversibility and uncertainty. Journal of Economic Dynamics \& Control, 19, 873-889. http://dx.doi.org/10.1016/j.jedc.2004.05.002

Pindyck, R. (1991). Irreversibility, uncertainty, and investment. Journal of Economic Literature, 29, 1110-1148

Reinganum, J. (1983). Uncertain innovation and the persistence of monopoly. American Economic Review, 73, 741-748

Weeds, J. (2002). Strategies delay in a real options model of R\&D competition. Review of Economics Studies, 69, $729-747$

Wong, K. (2011). Progressive taxation and the intensity and timing of investment. Economic Modelling, 28, 100-108. http://dx.doi.org/10.1016/j.econmod.2010.09.020

\section{Notes}

Note 1. Please refer to Dixit and Pindyck (1994).

Note 2. Tax revenues are positive when profits exceed zero.

Note 3. This result is implied by Pennings (2000) in which a combination of subsidy to investment and taxation on future profits with a zero expected revenue decreases the trigger value of investment. 
Note 4. Dixit and Pindyck (1994), Chapter 5.

Note 5. Policy $\mathrm{C}$ induces the same results as Policy A provided the investment is exogenous. Thus, in order to avoid redundancies and to have a direct comparison with Pennings (2000), Policy $\mathrm{C}$ is left out of section 2 which only discusses the case of exogenous investment.

Note 6. For Policy A, given the reduced critical value of investment, we derive $I A$ according to (45) and when $I A$ is known, we can determine $S$ from (43). In this way, the net tax revenues $\operatorname{Tax} A=\left[\left(t_{0} \theta^{*} I A^{*} V A\right) /\left(\gamma+\theta^{*} I A-\alpha\right)\right]-S$ are obtained. For Policy B, given the reduced critical value of investment, we determine $t_{1}$ from (46), and therefore, together with $I B$ by (44), the net tax revenues $\operatorname{Tax} B=\left[\left(t_{1} \theta^{*} I B^{*} V B\right) /\left(\gamma+\theta^{*} I B-\alpha\right)\right]$ can be derived. For Policy $\mathrm{C}$, given the reduced critical value of investment, we can derive $\tau$ from (47), and therefore, together with $I C$ by (44), the net tax revenues $\operatorname{Tax} C=\left[\left(t_{0} \theta * I C * V C\right) /(\gamma+\theta * I C-\alpha)\right]-\tau * I C$ can be determined.

\section{Appendix (Proof of proposition 2)}

For Policy A: Three conditions, the first order condition, the continuity condition and the smooth-? pasting condition, lead to the following three equations:

$$
\begin{aligned}
& \frac{\left(1-t_{0}\right) \theta^{*} V A(r-\alpha)}{\left(r+\theta^{*} I A-\alpha\right)^{2}}=1, \\
& A A^{*} V A^{\beta}=\frac{\left(1-t_{0}\right) \theta^{*} I A^{*} V A}{r+\theta^{*} I A-\alpha}-I A+S, \\
& \beta^{*} A A^{*} V A^{\beta-1}=\frac{\left(1-t_{0}\right) \theta^{*} I A}{r+\theta^{*} I A-\alpha} .
\end{aligned}
$$

We use these three equations to derive $I A, V A$ and $A A$, where

$$
I A=\frac{\frac{1}{\beta}+\sqrt{\left(\frac{1}{\beta}\right)^{2}-4 \frac{\beta-1}{\beta} \frac{\theta}{r-\alpha} S}}{2 \frac{\beta-1}{\beta} \frac{\theta}{r-\alpha}},
$$

and

$$
V A=\frac{1}{\theta \cdot(r-\alpha)} \times\left(r+\theta^{*} I A-\alpha\right)^{2} \times \frac{1}{\left(1-t_{0}\right)} .
$$

For Policy B: The same three conditions, the first order condition, the continuity condition and the smooth-pasting condition, lead to the following three equations:

$$
\begin{aligned}
& \frac{\left(1-t_{1}\right) \theta^{*} V B(r-\alpha)}{\left(r+\theta^{*} I B-\alpha\right)^{2}}=1, \\
& A B^{*} V B^{\beta}=\frac{\left(1-t_{1}\right) \theta^{*} I B * V B}{r+\theta^{*} I B-\alpha}-I B, \\
& \beta^{*} A B^{*} V B^{\beta-1}=\frac{\left(1-t_{1}\right) \theta^{*} I B}{r+\theta^{*} I B-\alpha} .
\end{aligned}
$$

We use these three equations to derive $I B, V B$ and $A B$, where

$$
I B=\frac{r-\alpha}{\theta(\beta-1)}
$$

and

$$
V B=\frac{1}{\left(1-t_{1}\right)}\left(\frac{\beta}{(\beta-1)}\right)^{2} \frac{r-\alpha}{\theta} .
$$

For Policy C: The same three conditions, the first order condition, the continuity condition and the smooth- pasting 
condition lead to the following three equations:

$\frac{\left(1-t_{0}\right) \theta^{*} V C(r-\alpha)}{\left(r+\theta^{*} I C-\alpha\right)^{2}}=(1-\tau)$,

$A C^{*} V C^{\beta}=\frac{\left(1-t_{0}\right) \theta^{*} I C^{*} V C}{r+\theta^{*} I C-\alpha}-(1-\tau) * I C$,

$\beta^{*} A C^{*} V C^{\beta-1}=\frac{\left(1-t_{0}\right) \theta^{*} I C}{r+\theta^{*} I C-\alpha}$.

We use these three equations to derive $I C, V C$ and $A C$, where

$I C=\frac{r-\alpha}{\theta(\beta-1)}$,

and

$V C=\frac{(1-\tau)}{1-t_{0}}\left(\frac{\beta-1}{\beta}\right)^{2} \frac{r-\alpha}{\theta}$.

Table 1. Net Tax Revenues for Different Policies under Various $\sigma$ and $\kappa^{*}$

\begin{tabular}{|c|c|c|c|}
\hline$(\sigma, \kappa)$ & Policy A & Policy B & Policy C \\
\hline$(0.05,0.80)$ & 1573 & 1406 & 2096 \\
\hline$(0.05,0.85)$ & 2672 & $* 2811$ & $* * 3329$ \\
\hline$(0.05,0.90)$ & 3958 & $* 4217$ & $* * 4562$ \\
\hline$(0.10,0.80)$ & $* * 5060$ & 2667 & 4667 \\
\hline$(0.10,0.85)$ & $* * 6845$ & 5333 & 6833 \\
\hline$(0.10,0.90)$ & 8829 & 8000 & $* * 9000$ \\
\hline$(0.15,0.80)$ & $* * 10169$ & 4390 & 8726 \\
\hline$(0.15,0.85)$ & $* * 12810$ & 8780 & 12032 \\
\hline$(0.15,0.90)$ & $* * 15665$ & 13170 & 15338 \\
\hline$(0.20,0.80)$ & $* * 17283$ & 6667 & 14667 \\
\hline$(0.20,0.85)$ & $* * 20967$ & 13333 & 19333 \\
\hline$(0.20,0.90)$ & $* * 24882$ & 20000 & 24000 \\
\hline
\end{tabular}

Notes: The parameters used are : $\alpha=0.01, r=0.1, \theta=0.000001, t_{0}=0.25$. "*" means the result that Policy B is better than Policy A, and “**" indicates the best policy for the given market volatility and reduced ratio in the table. 